\title{
MAPEAMENTO DO USO E COBERTURA DA TERRA DA ILHA DE SANTA CATARINA, BRASIL, COM BASE EM IMAGEM DE ALTA RESOLUÇÃO ESPACIAL
}

\author{
Jasiel Neves ${ }^{1}$ \\ Alexandre Ornon ${ }^{2}$ \\ Christine Voiron-Canicio ${ }^{3}$ \\ Norberto Olmiro Horn Filho ${ }^{4}$
}

\begin{abstract}
Resumo: Este trabalho apresenta um mapeamento do uso e cobertura da terra na Ilha de Santa Catarina com base em aerofotografias de alta resolução espacial e na vetorização da Restituição Aerofotogramétrica do Instituto de Planejamento Urbano de Florianópolis (IPUF), na escala 1:2.000. O método de interpretação das classes de mapeamento foi efetuado através da análise e interpretação visual de um mosaico aerofotogramétrico e o sistema de mapeamento foi organizado em 17 classes. Os resultados obtidos revelam o predomínio das classes de vegetação e do tecido urbano. As análises revelaram uma urbanização com densidade pontual e a presença de núcleos densos somente nas antigas áreas de povoamento, nas que abrigam grandes empreendimentos imobiliários ou de planejamento urbano.

Palavras-chave: Geografia; Sensoriamento remoto; Análise de imagens; Análise espacial; Ilha de Santa Catarina

\section{LAND USE AND LAND COVER MAPPING OF SANTA CATARINA ISLAND, SOUTHERN BRAZIL, USING HIGH-RESOLUTION AERIAL PHOTOGRAPHY}

\begin{abstract}
This paper presents a mapping of land use and land cover of Santa Catarina Island, in southern Brazil, based on high-resolution aerial photography and vectorization of aerophotogrammetric digital mapping at 1:2.000 scale produced by Urban Planning Institute of Florianopolis. The methodology adopted the visual analysis and interpretation of an aerial photogrammetric mosaic and the mapping method of land use patterns was organized into 17 classes. The results show the predominance of vegetation classes and urban areas. The patterns of urban areas are divided into continuous, discontinuous and diffuse categories, revealing punctual density and the presence of large urban areas only in the first settlements, real estate ventures or urban development projects.
\end{abstract}

Keywords: Geography; Remote sensing; Image analysis; Spatial analysis; Santa Catarina Island

\footnotetext{
1 Doutor em Geografia pela Universidade Federal de Santa Catarina (PPGGeo-UFSC) (www.ppggeo.ufsc.br) (jasiel.neves@ posgrad.ufsc.br). Bolsista PDSE da CAPES (www.capes.gov.br).

2 Doutorando do Laboratório ESPACE (UMR 7300) e da Universidade de Nice Sophia Antipolis (www.umrespace.org) (www.unice.fr).

3 Diretora do Laboratório ESPACE (UMR 7300) e Professora de Geografia da Universidade de Nice Sophia Antipolis (www.umrespace.org) (www.unice.fr).

4 Diretor do Departamento de Geociências e Professor de Geologia do Programa de Pós-graduação em Geografia da Universidade Federal de Santa Catarina (PPGGeo-UFSC) (www.ppggeo.ufsc.br).
} 


\section{MAPEO DE USO Y COBERTURA DE LA TIERRA DE LA ISLA DE SANTA CATARINA, BRASIL, CON BASE EN IMAGEN DE ALTA RESOLUCIÓN ESPACIAL}

Resumen: En el presente artículo se describe el mapeo de uso y cobertura de la tierra de la Isla de Santa Catarina con base en aerofotografías de alta resolución espacial y en la vectorización de la Restitución Aerofotogramétrica del Instituto de Planificación Urbana de Florianópolis, en la escala 1: 2.000. El método de interpretación de la cobertura y uso de la tierra se efectuó a través del análisis e interpretación visual de un mosaico aerofotogramétrico y el sistema de mapeo se organizó en 17 clases. Los resultados obtenidos revelan el predominio de las clases de vegetación y del tejido urbano. Los análisis revelaron una urbanización con densidad puntual y la presencia de núcleos densos solamente en las viejas áreas de poblamiento, en las que abrigan grandes emprendimientos inmobiliarios o de planificación urbana.

Palabras clave: Geografía; Teledetección; Análisis de imagen; Análisis espacial; Isla de Santa Catarina

\section{INTRODUÇÃO}

Ao retratar as formas e a dinâmica de uso da terra, os mapeamentos dessas feições representam um instrumento valioso para a construção de indicadores ambientais e para a avaliação da capacidade de suporte ambiental, contribuindo assim para a identificação de alternativas no ordenamento da ocupação humana (IBGE, 2006; EEA, 1999).

Com esse intuito, elaboramos um mapeamento do uso e cobertura da terra com precisão cartográfica em escala de detalhe (1:2.000) para a Ilha de Santa Catarina e comparamos os resultados obtidos com outras análises publicadas sobre o tema na área de estudo, como os trabalhos de Caruso (1990), Campos (1991) e Ferretti (2013).

A área de estudo está localizada na região Sul do Brasil, constitui a parte insular do município de Florianópolis e situando-se entres as coordenadas $27^{\circ} 22^{\prime} 49,65^{\prime}$ ' e $27^{\circ} 50^{\prime}$ 36,65 ” de latitude Sul, e $48^{\circ} 25^{\prime}$ '01,37' e $48^{\circ} 33^{\prime} 36,64$ ” de longitude Oeste, perfazendo uma área de $421,98 \mathrm{~km}^{2}$.

A Ilha de Santa Catarina é separada do continente próximo pela baía de Florianópolis, subdividida em duas baías, denominadas baía Norte e baía Sul, que são divididas por um estreito canal onde se localizam as vias de ligação entre as partes insular e continental do município supracitado, as pontes Colombo Machado Salles e Pedro Ivo Campos. O local de estudo está disposto nas imediações das áreas territoriais continentais dos municípios de Biguaçu, Governador Celso Ramos, Florianópolis, Palhoça e São José (Figuras 1 e 2), além de apresentar uma costa oceânica, conforme as Figuras 3 e 4 apresentadas a seguir.

O município de Florianópolis, por sua vez, foi dividido em 12 distritos e 133 Unidades de Planejamento Espacial (UEPs), adotados em 1980 pelo Instituto de Planejamento Urbano 
de Florianópolis (IPUF) para a administração pública da capital do Estado de Santa Catarina, conforme apresentado a seguir nas Figuras 5 e 6.

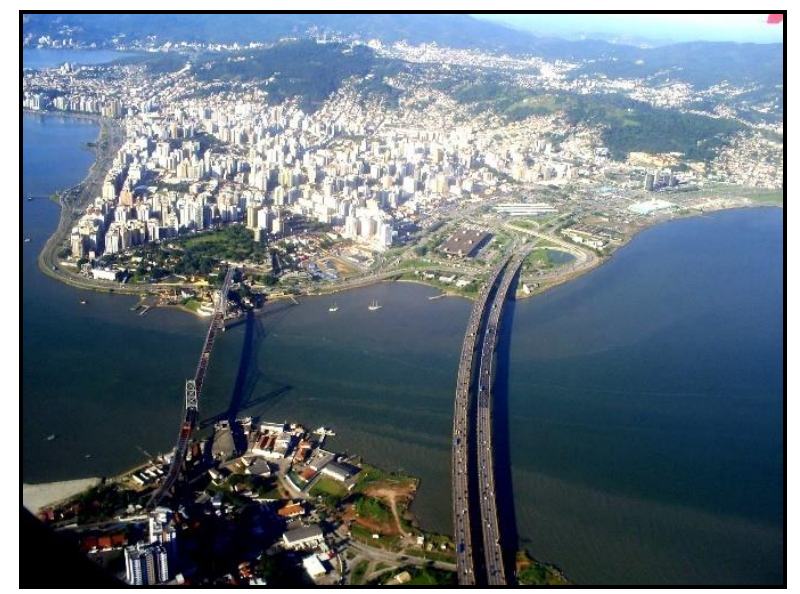

Figura 1 - Vista aérea do canal do Estreito, na baía de Florianópolis (Data: 30/04/2008).

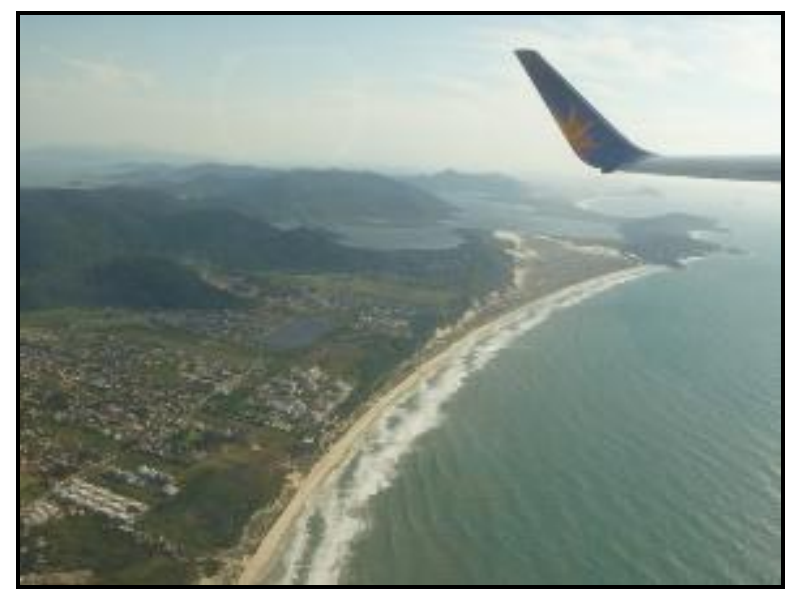

Figura 3 - Costa oceânica da Ilha de Santa Catarina a partir do Distrito do Campeche no sentido do Distrito da Lagoa da Conceição (Data: 13/08/2012).

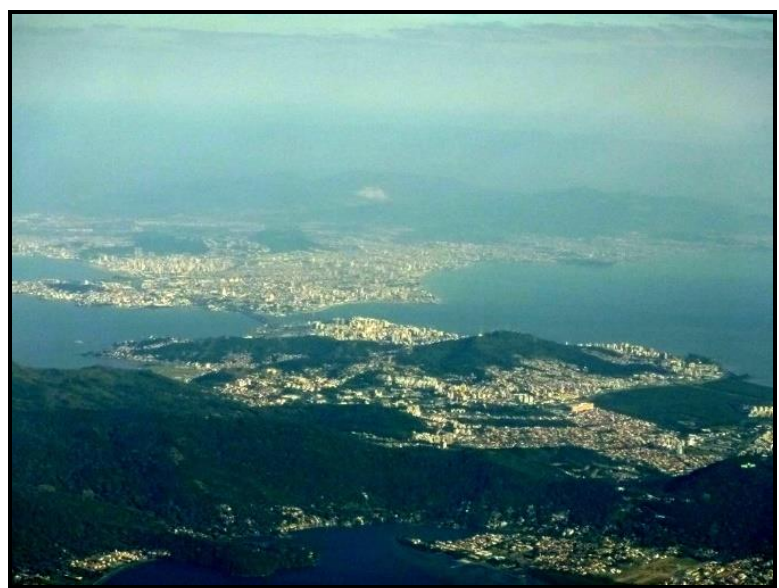

Figura 2 - Vista aérea das baías Norte (à direita) e Sul (à esquerda), no sentido Lagoa da Conceição - Morro da Cruz (Data: 30/04/2008).

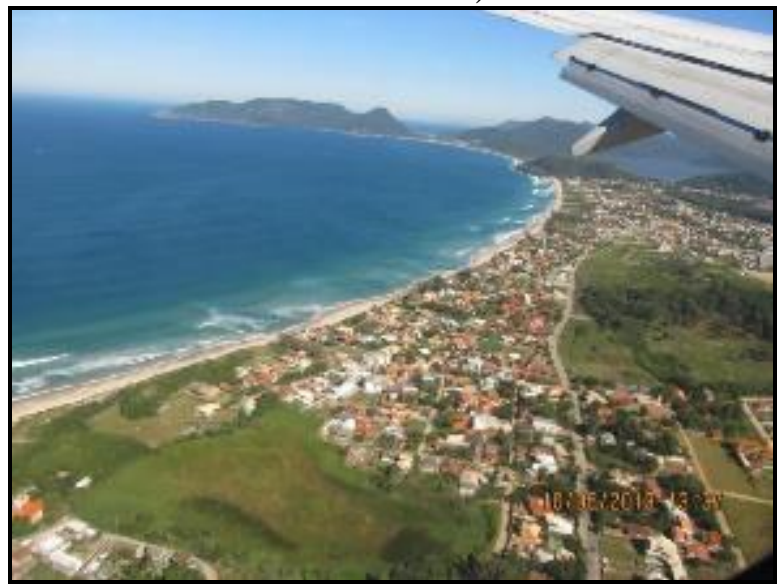

Figura 4 - Costa oceânica da Ilha de Santa Catarina a partir do Distrito do Campeche no sentido do Distrito do Pântano do Sul (Data: 13/08/2012). 


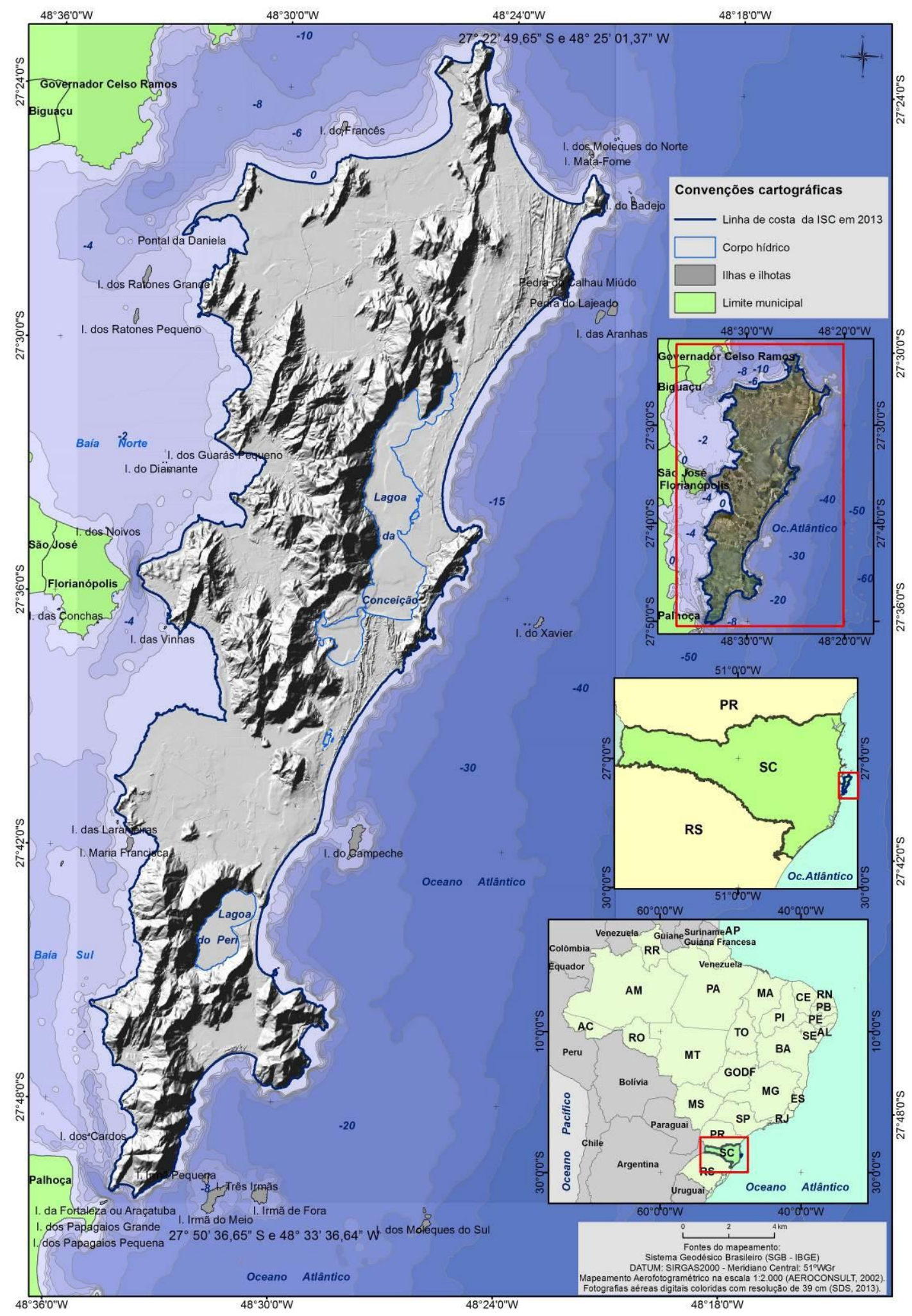

Figura 5 - Localização da Ilha de Santa Catarina (Fonte: NEVES, 2017). 


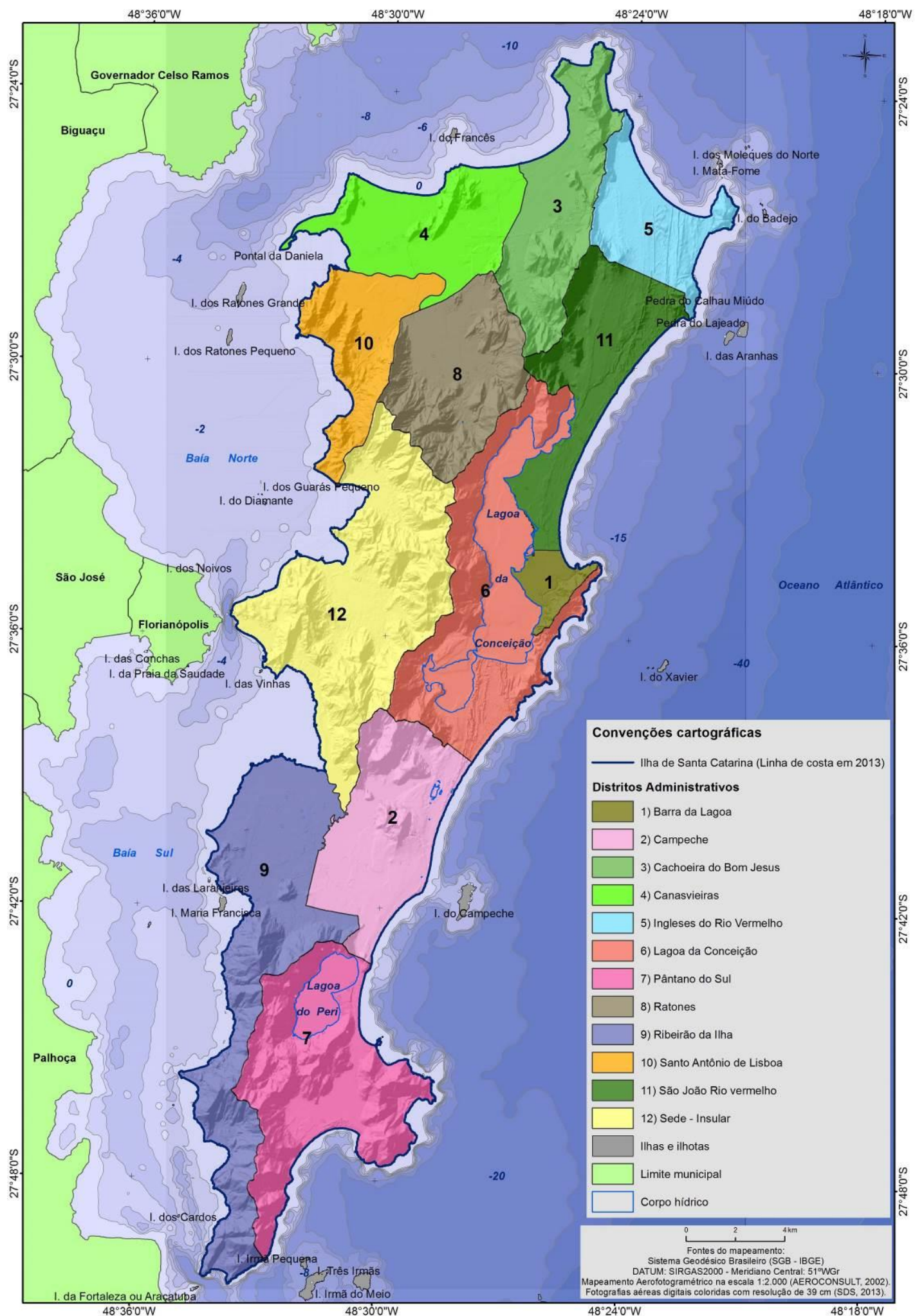

Figura 6 - Distribuição territorial dos distritos administrativos do município de Florianópolis na Ilha de Santa Catarina (Fontes: NEVES, 2017 e IPUF, 2002).

METODOLOGIA

A unidade de mapeamento é a representação da homogeneidade e diversidade de objetos que recobrem a superfície da terra. Corresponde à cobertura considerada homogênea 
(floresta, campo, água, área urbana, etc.) ou à combinação de áreas elementares que em suas variações representam a cobertura da superfície terrestre, caracterizando-se por ser claramente distinguível das unidades de seu entorno e por representar um objeto, forma ou padrão em uma dada escala de mapeamento (IBGE, 2006).

Os métodos adotados nessa pesquisa organizaram as unidades de mapeamento em 17 classes de interpretação das feições de uso e cobertura da terra, sendo: 1) agricultura; 2) aterro; 3 ) área úmida; 4) corpo d’água; 5) costão/rocha; 6) duna; 7) estrada; 8) manguezal; 9) praia; 10) reflorestamento; 11) solo exposto; 12) urbanização difusa; 13) urbanização descontínua; 14) urbanização contínua; 15) vegetação herbácea, 16) vegetação arbustiva e 17) vegetação arbórea. Esses elementos deram subsídio para a identificação e quantificação dos ambientes costeiros e depósitos tecnogênicos existentes na área de estudo, conforme Neves (2017).

Todas as atividades de interpretação de imagem foram elaboradas com classificação dos polígonos de uso e da cobertura da terra de forma visual sobre um ortofotomosaico colorido (formato RBG) com resolução espacial de $39 \mathrm{~cm}$ e escala 1:2.000, com fotografias aéreas tomadas no ano de 2013, recobrindo toda área da Ilha $\left(421,98 \mathrm{~km}^{2}\right)$. O referido mosaico é produto integrante do Levantamento Aerofotogramétrico do Governo do Estado de Santa Catarina no âmbito das atividades da Secretaria de Estado do Desenvolvimento Econômico e Sustentável (SDS, 2016). De acordo com os executores desse produto de Sensoriamento Remoto (SDS, 2016; FURLANETTI, 2016 e ENGEMAP, 2016), o grande diferencial do mesmo no escopo da Cartografia Brasileira consiste na sua precisão e no seu nível de detalhamento, sendo possível identificar qualquer objeto no solo com dimensão maior do que um metro de comprimento.

O ortofotomosaico supracitado foi associado em ambiente de Sistema de Informação Geográfica (SIG) às 449 plantas topográficas na escala 1:2.000 da Restituição Aerofotogramétrica do Instituto de Planejamento Urbano de Florianópolis (IPUF, 2002), conforme as Figuras 7 a 10, apresentadas a seguir. 


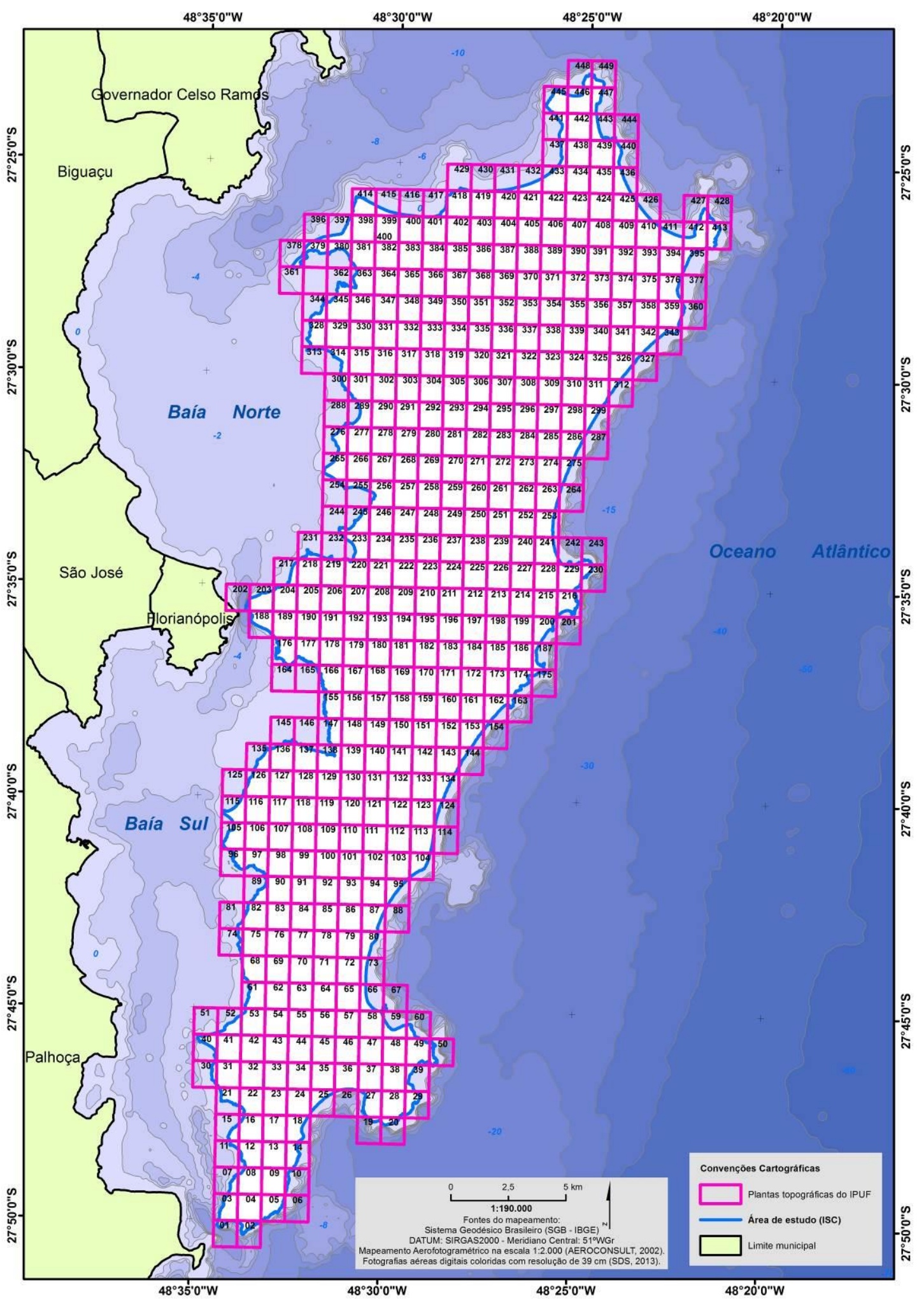

Figura 7 - Articulação das plantas topográficas do IPUF e a delimitação da área de estudo (Fonte: NEVES, 2017). 


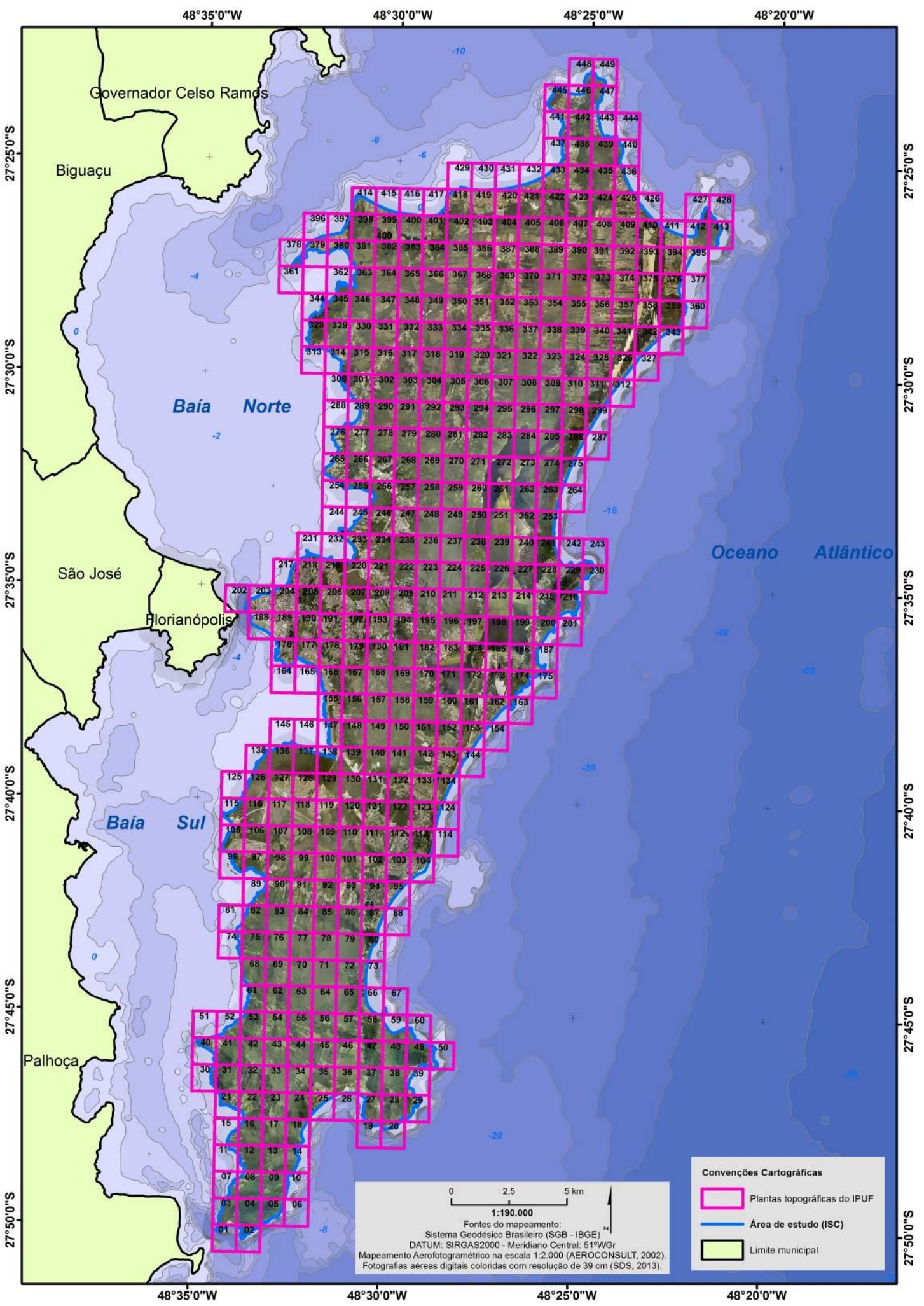

Figura 8 - Associação das plantas topográficas do IPUF ao ortofotomosaico de $2013 \mathrm{em}$ ambiente SIG (Fonte: NEVES, 2017). 


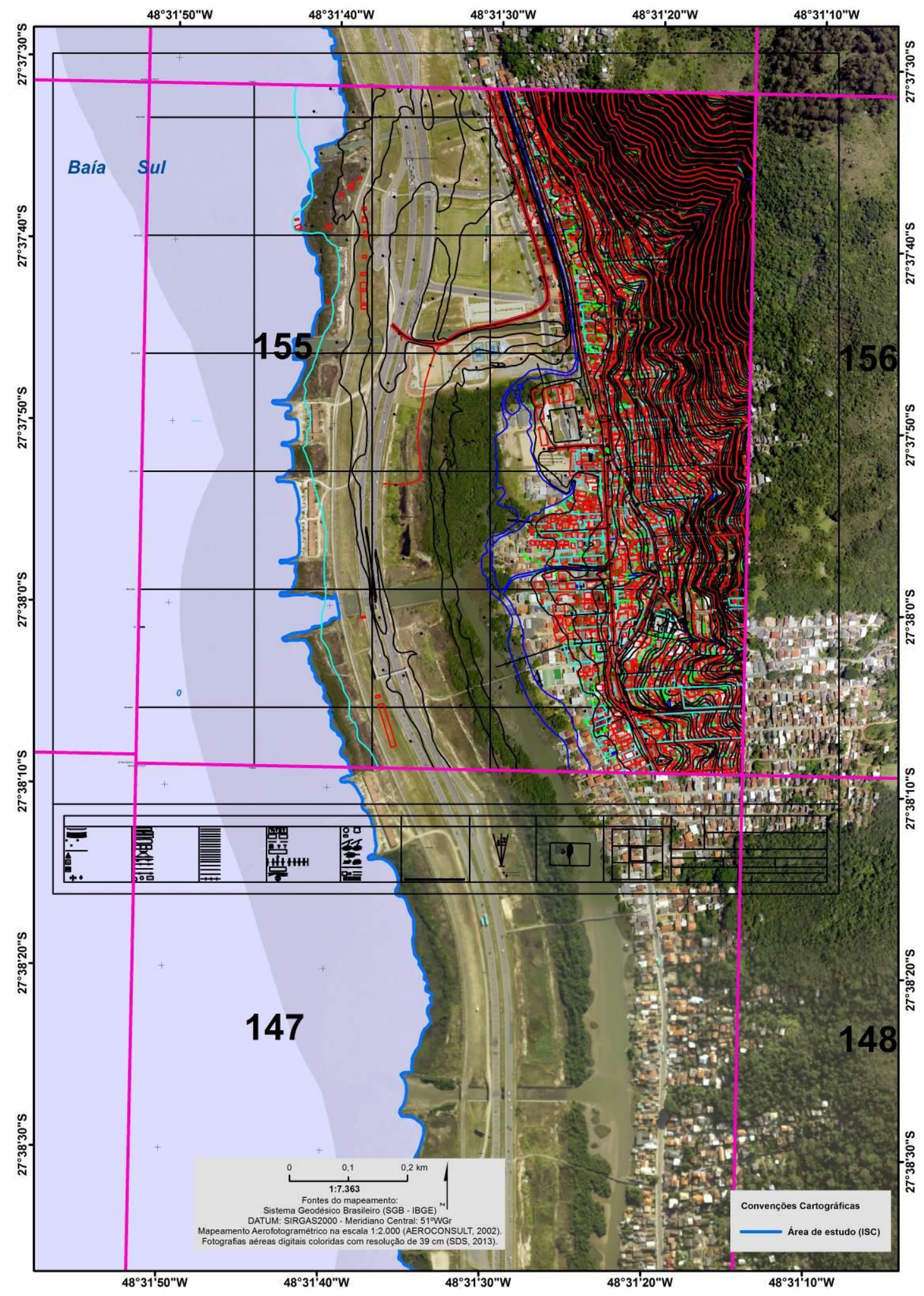

Figura 9 - Detalhe das plantas topográficas $n^{\circ}$ 147; 148; 155 e 156 associadas ao ortofotomosaico em ambiente SIG (Fonte: NEVES, 2017). 


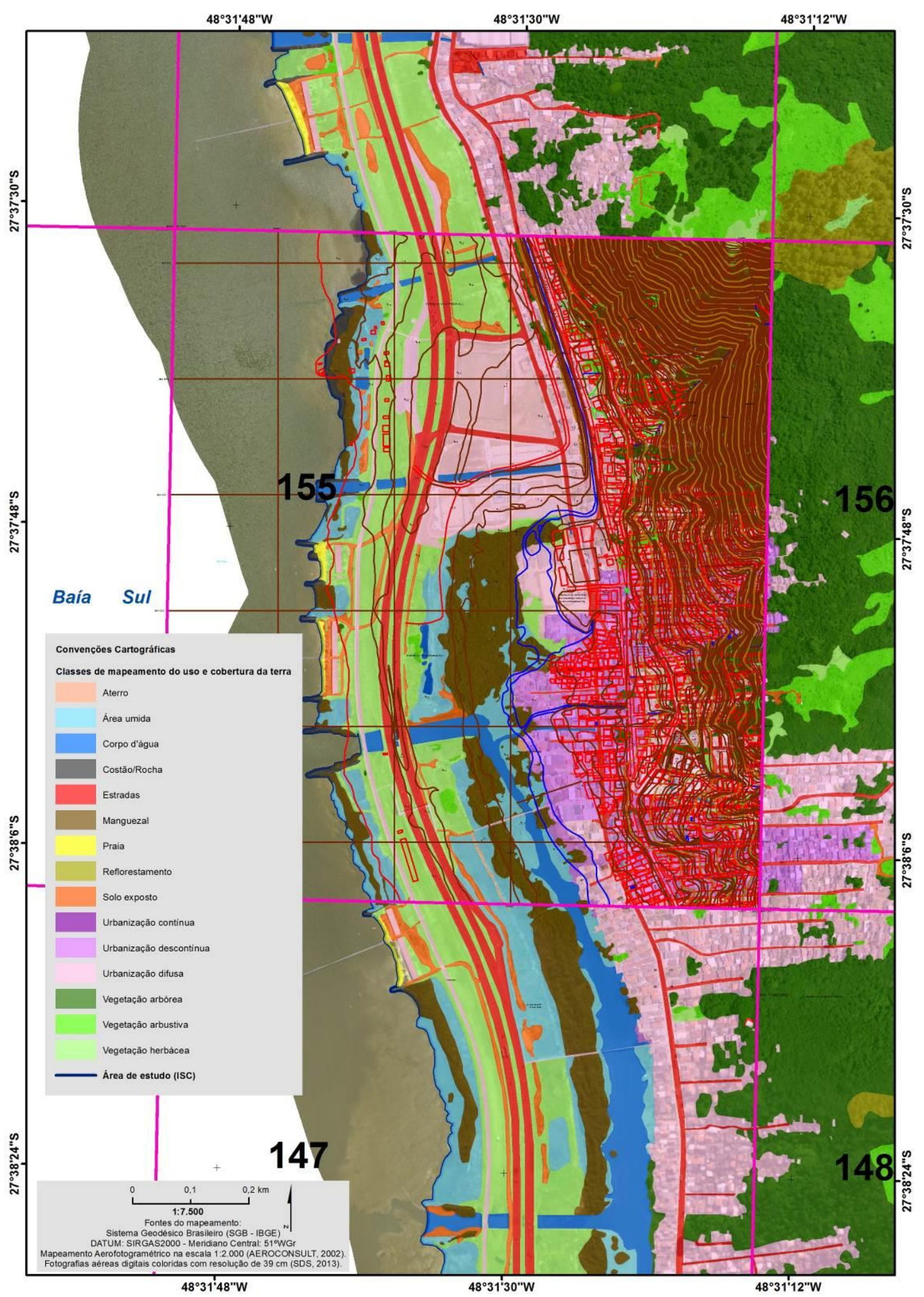

Figura 10 - Planta topográfica ${ }^{\circ} 155$ associada em ambiente SIG ao mapeamento do uso e cobertura da terra executado nessa pesquisa (Fonte: NEVES, 2017).

\section{RESULTADOS E DISCUSSÃO}


A síntese das áreas e porcentagens das classes de uso e cobertura da terra na Ilha de Santa Catarina obtida através do mapeamento com base em imagem de alta resolução espacial está descrita no Quadro 1, apresentado abaixo, e na Figura 11, apresentada a seguir.

Quadro 1 - Síntese das áreas e porcentagens das classes de uso e cobertura da terra na Ilha de Santa Catarina em 2013.

\begin{tabular}{|c|c|c|c|}
\hline Uso & Area $\mathbf{( k m}^{\mathbf{2}} \mathbf{)}$ & Hectares (ha) & Porcentagem (\%) \\
\hline Vegetação arbórea & 186,70 & $18.669,82$ & 44,24 \\
\hline Urbanização difusa & 40,32 & $4.031,68$ & 9,55 \\
\hline Vegetação arbustiva & 38,18 & $3.817,54$ & 9,05 \\
\hline Vegetação herbácea & 37,20 & $3.720,27$ & 8,82 \\
\hline Corpo d'água & 29,07 & $2.907,15$ & 6,89 \\
\hline Área úmida & 24,84 & $2.483,68$ & 5,89 \\
\hline Manguezal & 17,23 & $1.722,61$ & 4,08 \\
\hline Urbanização descontínua & 11,39 & $1.139,30$ & 2,70 \\
\hline Estrada & 9,53 & 952,82 & 2,26 \\
\hline Reflorestamento & 8,80 & 879,68 & 2,08 \\
\hline Duna & 6,92 & 692,02 & 1,64 \\
\hline Solo exposto & 5,25 & 524,62 & 1,24 \\
\hline Praia & 1,96 & 195,51 & 0,46 \\
\hline Costão/Rocha & 1,48 & 148,24 & 0,35 \\
\hline Agricultura & 1,33 & 132,98 & 0,32 \\
\hline Urbanização contínua & 1,28 & 127,59 & 0,30 \\
\hline Aterro & 0,52 & 52,35 & 0,12 \\
\hline Total & 421,98 & $42.197,86$ & 100 \\
\hline
\end{tabular}

(Fonte: NEVES, 2017).

As análises efetuadas por esta pesquisa revelaram que, no momento da tomada das aerofotografias que deram origem ao ortofotomosaico analisado, no ano de 2013, as classes de cobertura da terra mais representativas na Ilha eram as formações vegetais, que totalizavam $262,08 \mathrm{~km}^{2}$ ou $62,10 \%$ da área de estudo, se somadas as feições arbórea, arbustiva e herbácea, conforme apresentado a seguir na Figura 11.

Se as feições supracitadas forem analisadas de forma distinta, a classe mais representativa era a da vegetação arbórea, com $186,70 \mathrm{~km}^{2}(44,24 \%)$, seguida pelas vegetações arbustiva, com $38,18 \mathrm{~km}^{2}(9,05 \%)$ e herbácea, com $37,20 \mathrm{~km}^{2}(8,82 \%)$ (ver a Figura 11, a seguir). 


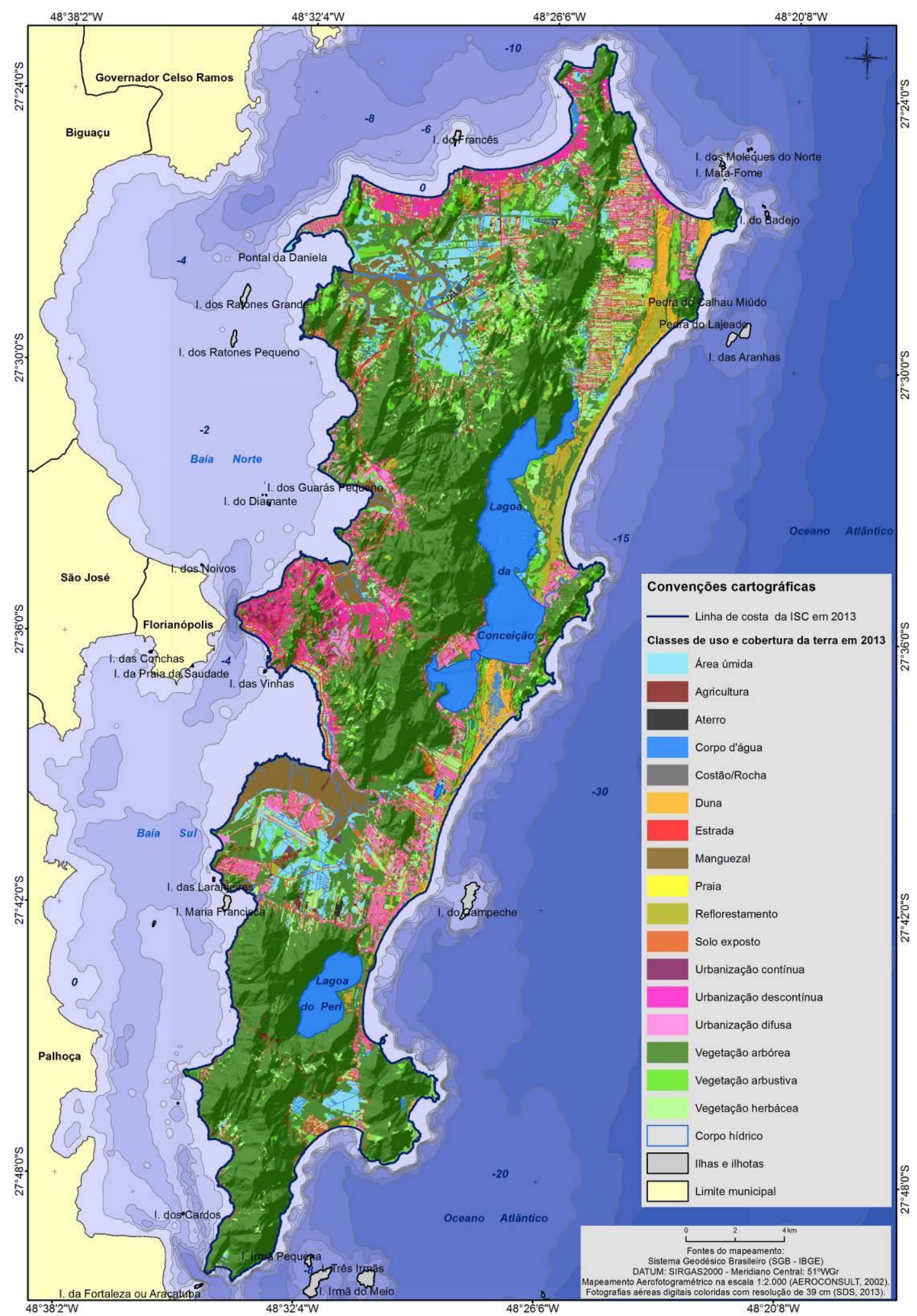

Figura 11 - Mapeamento das classes de uso e cobertura da terra da Ilha de Santa Catarina com base em imagem de alta resolução espacial no ano de 2013 (Fonte: NEVES, 2017).

No Gráfico 1, apresentado abaixo, é possível visualizar o significativo predomínio da classe de vegetação arbórea sobre as demais classes analisadas no âmbito deste mapeamento, demonstrando a representativa recuperação e regeneração da vegetação após o declínio das 
atividades agrícolas, que ocupam atualmente $1,33 \mathrm{~km}^{2}(0,32 \%)$ da Ilha. Cabe salientar aqui, que em suas análises de mapeamento do uso e cobertura da terra na área de estudo, com fotografias aéreas de 1938 e 1978, Caruso (1990, p.103) determinou que a Agricultura foi o principal tipo de uso da terra responsável pelo desmatamento, visto que o mesmo arrasava por completo os fragmentos florestais.

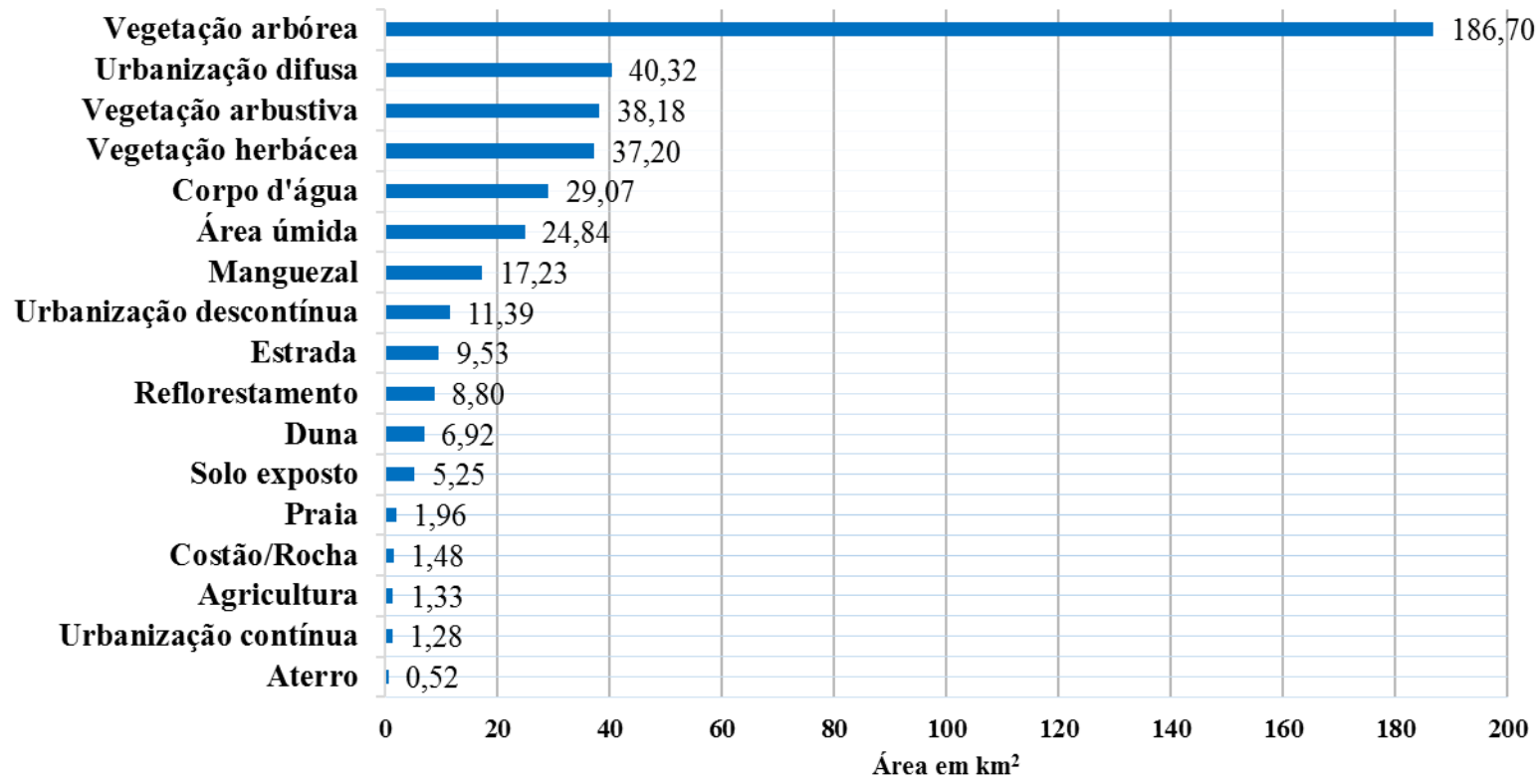

Gráfico 1 - Representação das áreas ocupadas pelas classes de uso e cobertura da terra, em $\mathrm{km}^{2}$, no mapeamento efetuado na Ilha de Santa Catarina em 2013, com predomínio da vegetação arbórea (Fonte: NEVES, 2017).

É importante observar, também, que os locais onde os fragmentos floreais mais se recuperaram se localizam acima da cota altimétrica de 60 metros, que Campos (1991, pag.108) apontou serem antigas áreas florestais com possibilidade de uso comunal na Ilha. Essas áreas citadas acabaram sendo protegidas pela promulgação dos planos diretores do Município de Florianópolis, conforme apresentado a seguir nas Figuras 12, 13 e 14, na forma de Áreas de Preservação de Uso Limitado (APL) (FLORIANÓPOLIS, 1985 e 1997) e Áreas de Preservação com Uso Limitado de Encosta (APL-E) e de Planície (APL-P) ou de Áreas de Preservação Permanente (APP) (FLORIANÓPOLIS, 2014). 


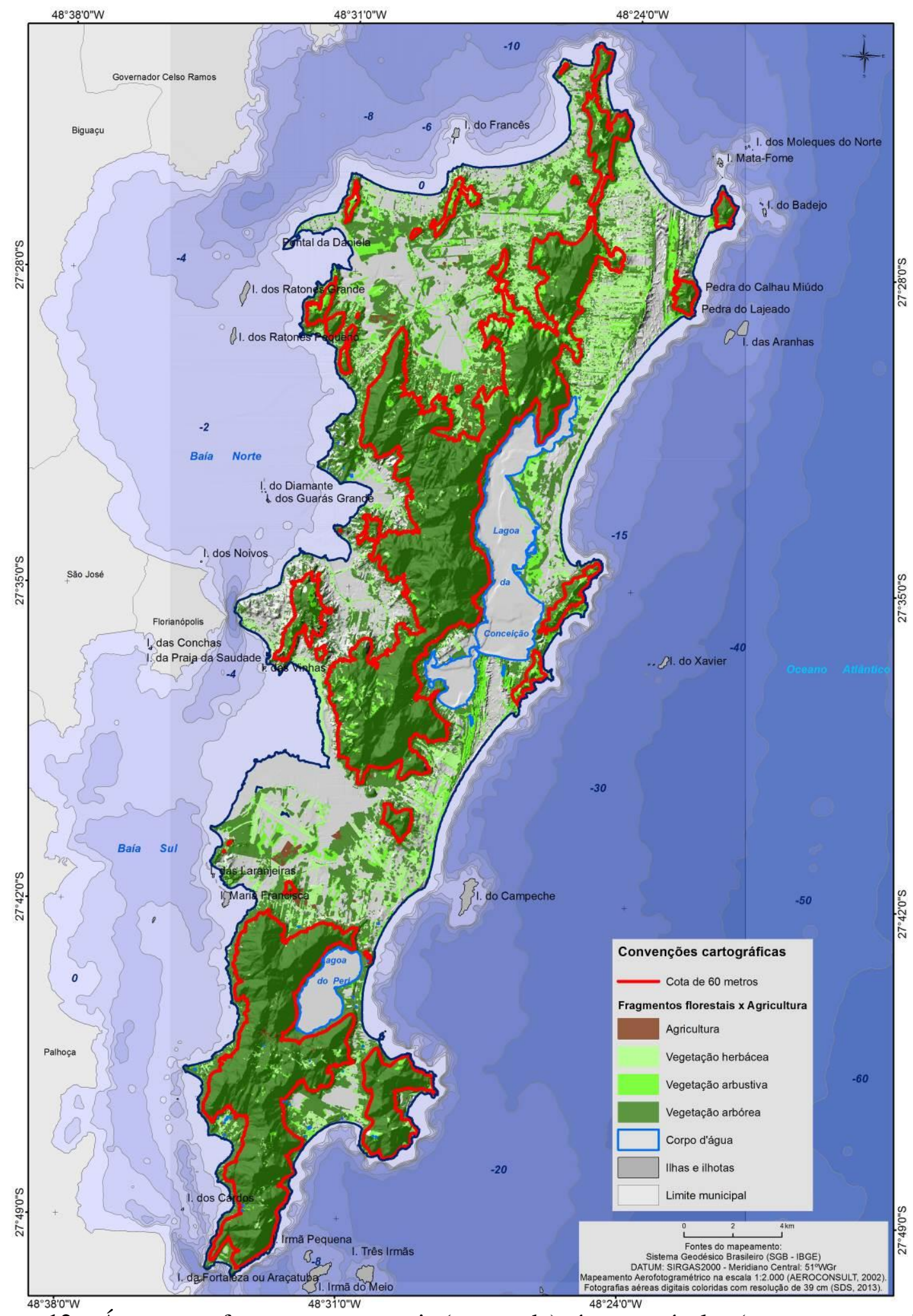

Figura 12 - Áreas com fragmentos vegetais (em verde), áreas agrícolas (pontos marrons) e a cota de 60 metros (polígonos vermelhos) no ano de 2013 (Fonte: NEVES, 2017). 


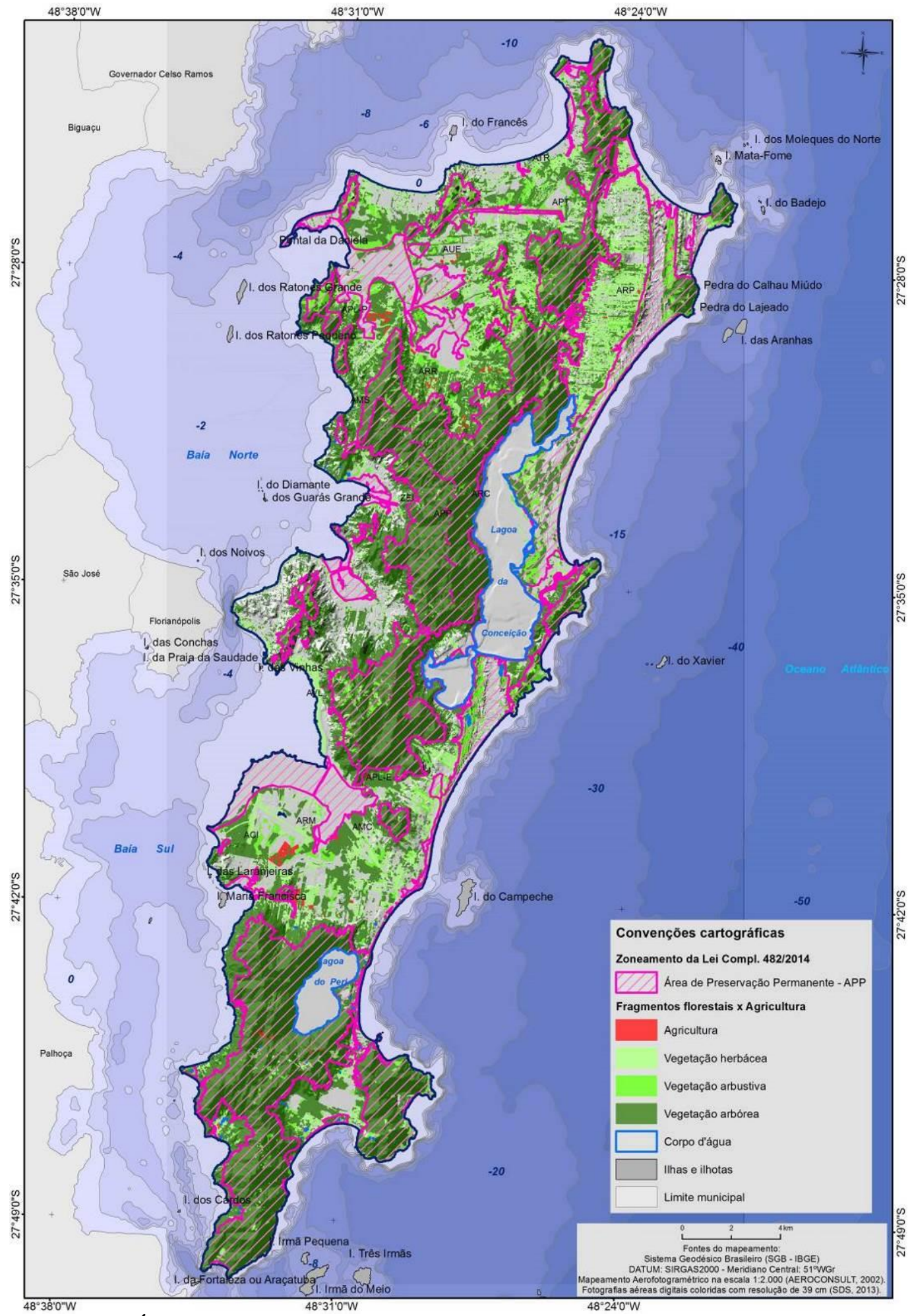

Figura 13 - Áreas de APP (polígonos hachurados em magenta) e sua relação com os fragmentos florestais (manchas verdes) e áreas agrícolas (manchas vermelhas) no ano de 2013 (Fonte: NEVES, 2017). 


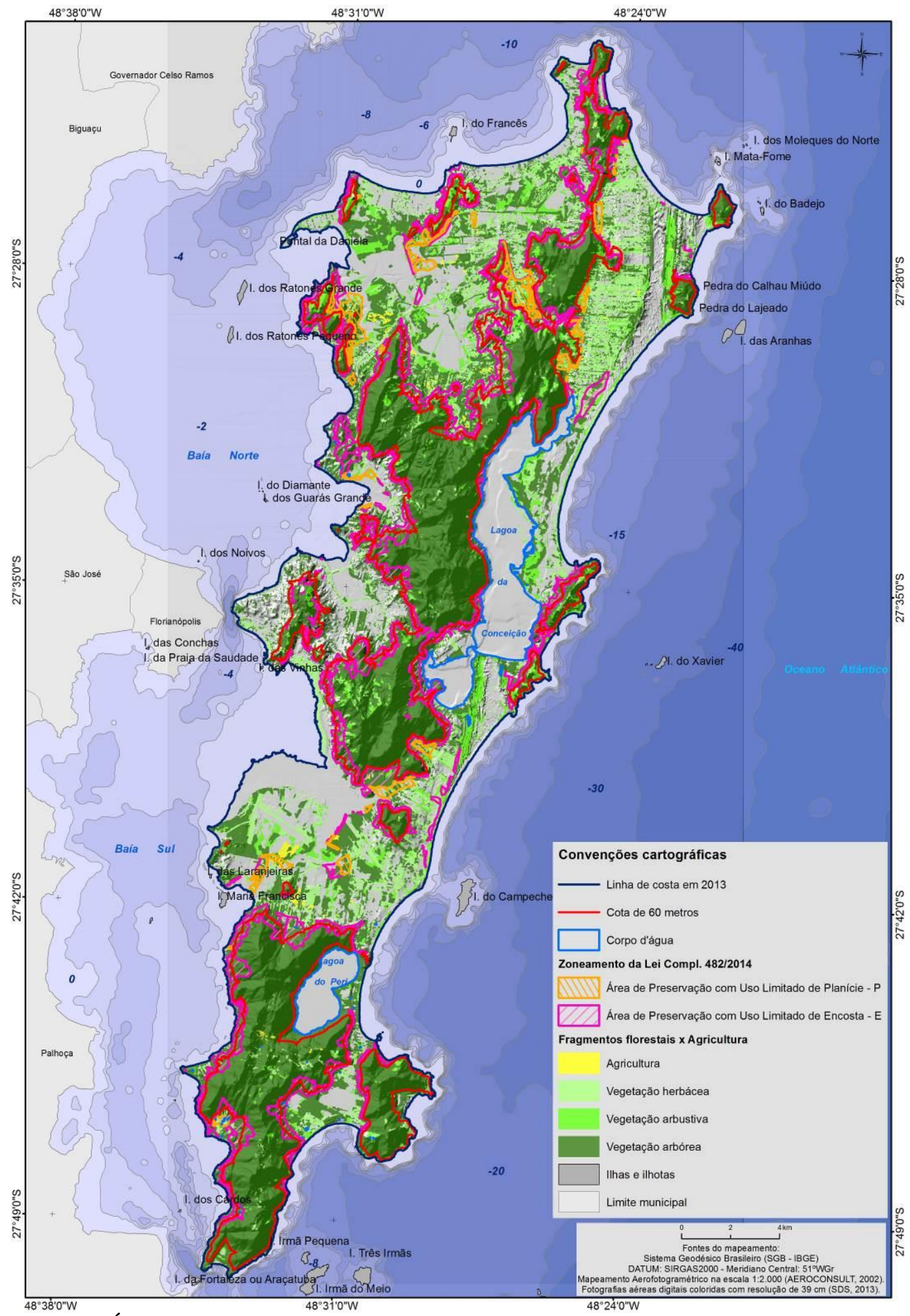

Figura 14 - Áreas de APL-P (polígonos alaranjados), APL-E (polígonos magentas) e sua relação com a cota altimétrica de 60 metros (polígonos vermelhos), fragmentos florestais (manchas verdes) e áreas agrícolas (manchas amarelas) no ano de 2013 (Fonte: NEVES, 2017).

As Áreas de Preservação Permanente (APP) representam 51,45\% da área de estudo (Figura 15) e os planos diretores (FLORIANÓPOLIS, 1985; 1997 e 2014) estabeleceram-nas como não edificáveis (non aedificandi), sendo nelas vedado parcelamento do solo ou 
quaisquer intervenções, salvo nos casos de utilidade pública, além da proibição da supressão florestal em qualquer estágio da vegetação. Essas condicionantes colaboraram para a recuperação dos fragmentos vegetais e o predomínio da vegetação arbórea nessas áreas protegidas, sacramentando a proteção desses espaços após regulamentação federal na década de 1960.

Somada à proteção das feições da vegetação oferecida pelos zoneamentos territoriais do município de Florianópolis instituídos pelos planos diretores citados (FLORIANÓPOLIS, 1985; 1997 e 2014), pode ser acrescentado o destaque de FERRETTI (2013, p. 138) à importância decisiva da criação efetiva de unidades de conservação na área de estudo a partir da década de 1980, que esse autor denominou Espaços de Natureza Protegida (ENP).

Ressaltamos que, no âmbito do mapeamento executado nessa pesquisa, existem outras classes de cobertura vegetal que não foram contabilizadas entre as formações vegetais arbóreas, arbustivas e herbáceas, sendo exemplos disso as formações vegetais presentes nos manguezais, que ocupam uma área de $17,23 \mathrm{~km}^{2}$ (4,08\%); as áreas úmidas (banhados, brejos, várzeas e marismas) com $24,84 \mathrm{~km}^{2}$ (5,89\%) e os reflorestamentos (espécies exóticas), com área de $8,80 \mathrm{~km}^{2}(2,08 \%)$. Se somadas, essas áreas perfazem um total de $50,87 \mathrm{~km}^{2}(12,05 \%) \mathrm{e}$ assumem representatividade nas classes de cobertura da terra na área de estudo.

As demais classes de cobertura da terra mapeadas são representadas pelos corpos d'água, muito representativos em todo território da Ilha, com 29,07km² (6,89\%); os campos de duna e as dunas frontais de alguns sistemas praiais da área de estudo, que representam uma área de $6,92 \mathrm{~km}^{2}(1,64 \%)$. Além da classe praia, com $1,96 \mathrm{~km}^{2}(0,46 \%)$ e a classe dos costões e rochas, constituída por afloramentos de matacões muito perceptíveis na imagem analisada e costões rochosos ou falésias marinhas, com área de $1,48 \mathrm{~km}^{2}(0,35 \%)$.

Mesmo apresentando pequena quantidade em relação à área total da Ilha, essas duas últimas classes possuem uma dispersão considerável ao longo de toda área de estudo e apresentam-se de forma numerosa, se tivermos por base a resolução espacial da imagem utilizada na interpretação das classes de mapeamento.

No que diz respeito às classes de uso da terra, as áreas urbanizadas assumem o predomínio dessas feições com um total de $52,99 \mathrm{~km}^{2}$, ou $12,55 \%$ da área de estudo, sendo que no âmbito do mapeamento em comento a urbanização foi dividida em três níveis de densidade: urbanização contínua, urbanização descontínua e urbanização difusa, com base no processo de propagação da urbanização descrito por Voiron-Canicio (1995, p.90 e 2006, p.6), segundo a distribuição dessas feições geográficas e suas respectivas texturas, superfícies e 
densidades na imagem analisada, com o apoio dos vetores dos polígonos das plantas aerofotogramétricas descritas na metodologia desse artigo.

Entre esses três níveis de urbanização mapeados, predomina o difuso, com um total de $40,32 \mathrm{~km}^{2}(9,55 \%)$, geralmente, dominado por unidades unifamiliares constituídas por um pavimento e situadas nos setores do zoneamento territorial onde as taxas de Ocupação e Impermeabilização, além do Afastamento Obrigatório, são mais restritivos, com destaque para: Área Residencial Rural (ARR); Área Residencial Cultural (ARC); Área de Urbanização Especial (AUE); Área Residencial Predominante (ARP); Área Turística Residencial (ATR); Área Turística e de Lazer (ATL) e Área Residencial Mista (ARM), conforme os usos determinados pelo Plano Diretor do Município de Florianópolis (FLORIANÓPOLIS, 2014), apresentado a seguir nas Figuras 15 e 16.

O caráter difuso predomina também em áreas nas quais são vedados os usos residenciais, mas ocorre a presença de edificações, como na Área Comunitária Institucional (ACI) e na Área Verde de Lazer (AVL) (Figuras 15 e 16).

Secundariamente, aparecem as áreas com urbanização descontínua, que ocupam 11,39 $\mathrm{km}^{2}(2,70 \%)$ e estão relacionadas, majoritariamente, às Área de Urbanização Especial (AUE); Área Residencial Predominante (ARP); Área Turística Residencial (ATR); Área Turística e de Lazer (ATL); Área Residencial Mista (ARM); Área Mista de Serviço (AMS) e Área Mista Central (AMC), destinadas aos usos residenciais, comerciais e de serviços, com alta densidade habitacional (Figuras 15 e 16).

Por fim, ocorrem as áreas de urbanização contínua, com $1,28 \mathrm{~km}^{2}(0,30 \%)$ e alta densidade habitacional associadas às AMCs do Polígono Central do Distrito Sede, com taxas de Ocupação e Impermeabilização entre 100 e $80 \%$ das glebas (Figuras 15 e 16). 


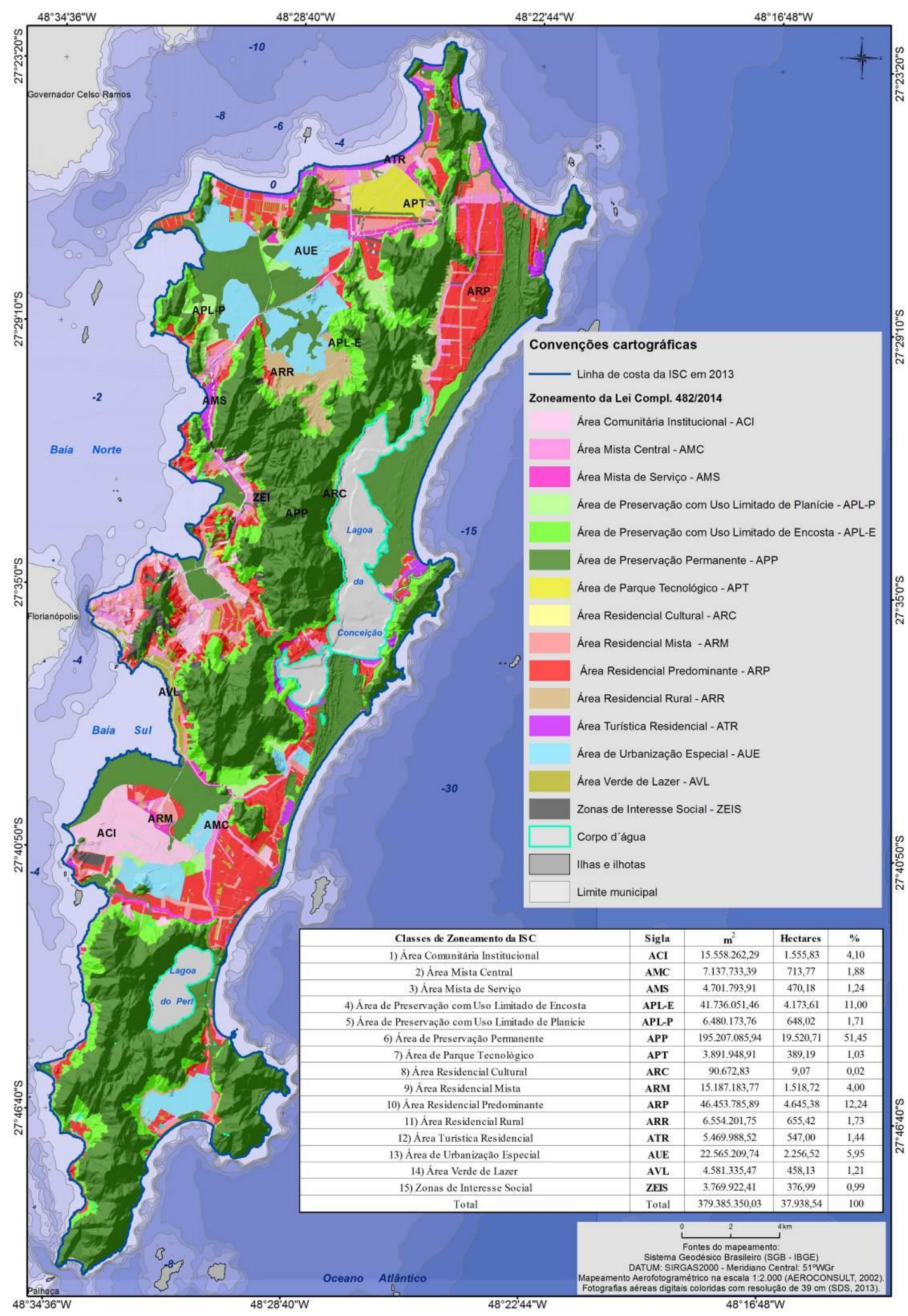

Figura 15 - Zoneamento da Lei Complementar n482/2014 que instituiu o Plano Diretor de Urbanismo do Município de Florianópolis e da Ilha de Santa Catarina (Fonte: NEVES, 2017). 


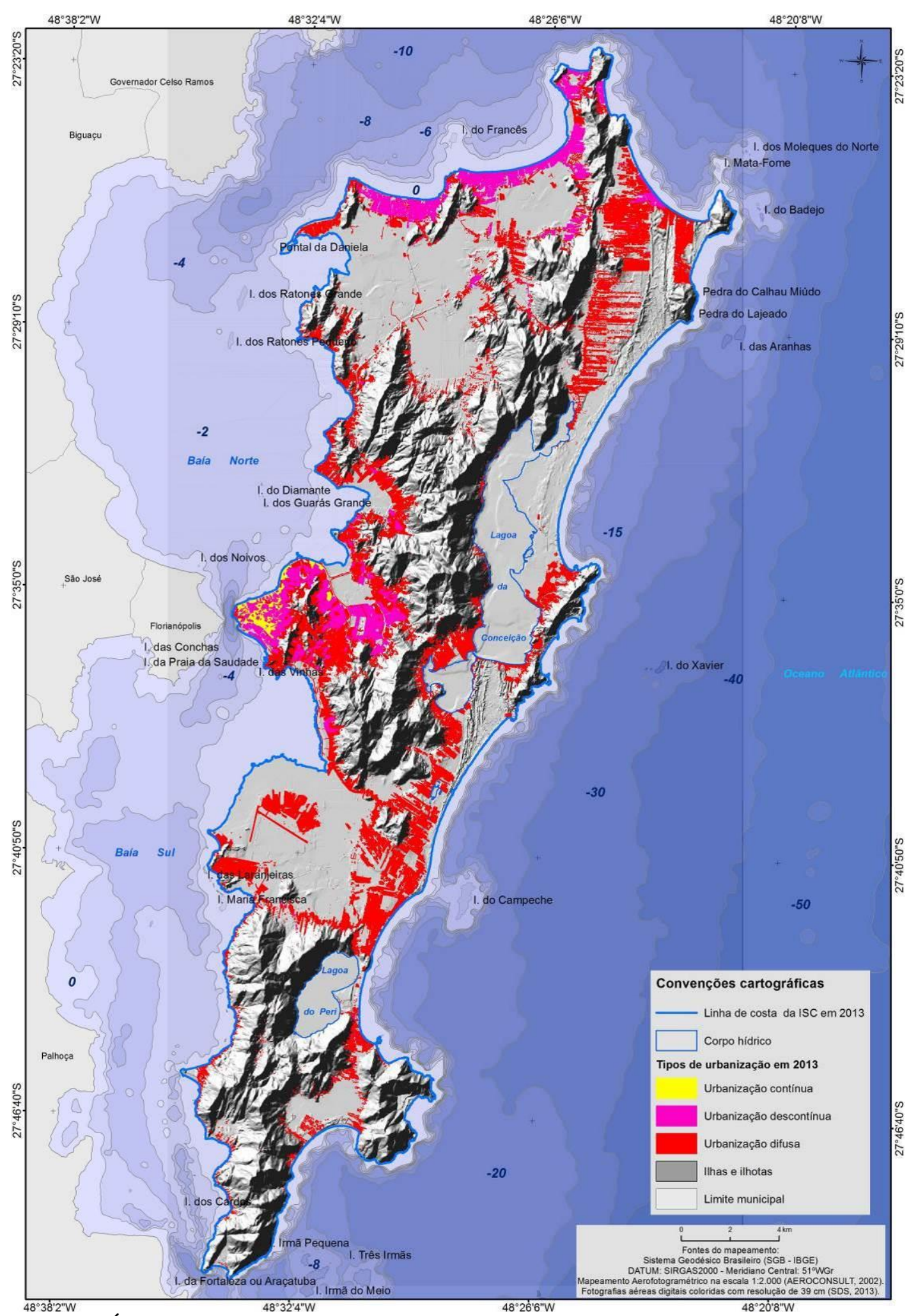

Figura 16 - Áreas urbanas da Ilha de Santa Catarina (contínuas: em amarelo; descontínuas: em magenta e difusas: em vermelho) no ano de 2013 (Fonte: NEVES, 2017).

As áreas de urbanização contínua são restritas ao Distrito Sede e ao sítio urbano primordial da ocupação da Ilha, representando os locais com maior densidade populacional e de edificações da área de estudo, com setores censitários que agregam entre 18.000 e 361.000 
hab./km², de acordo com os dados do Censo Demográfico de 2010 (IBGE, 2016), conforme apresentado a seguir na Figura 17.

Completando as classes de uso da terra, estão as áreas ocupadas com atividades agrícolas, com 1,33km² (0,32\%); frequentes nos distritos do Ribeirão da Ilha, do Pântano do Sul, de Ratones e outros locais dispersos na forma de pequenas propriedades. Os locais com aterros, na época da tomada das imagens aéreas, no ano de 2013 , possuíam $0,52 \mathrm{~km}^{2}(0,12 \%)$, estando geralmente relacionados à implantação de empreendimentos imobiliários, aberturas de canais de drenagem e acúmulo de material terrígeno nos seus leitos. Ressaltamos que os aterros pretéritos das baías Norte e Sul foram interpretados com a feição que recobria os mesmos na imagem analisada.

Somam-se às duas últimas classes, as estradas de todos os tipos de pavimentação, com $9,53 \mathrm{~km}^{2}(2,26 \%)$ e as áreas com solo exposto, representadas por $5,25 \mathrm{~km}^{2}(1,24 \%)$, que estão associadas às atividades de terraplanagem, trilhas e supressão de vegetação.

Com base nos dados dos censos do IBGE, Neves (2017) registrou um aumento de 347.501 habitantes nos anos com contagem da população a partir do momento em que a paisagem da área de estudo passa a apresentar feições de crescimento urbano, entre os anos de 1970 e 2013, sendo que existe a nítida tendência do aumento de hab. $/ \mathrm{km}^{2}$ nesse período, refletindo uma ilha muito povoada no início do Século XXI. Segundo o autor citado, essa condicionante é reforçada pelos vetores da verticalização das edificações; da pressão sobre as áreas de preservação e conservação, que representam mais de $50 \%$ do território da Ilha; no adensamento das áreas subnormais, além da perda e modificação do patrimônio histórico e arqueológico, conforme apresentado abaixo no Quadro 2, no Gráfico 2 e na Figura 17.

O mapeamento das classes de uso e cobertura da terra que efetuamos, também propiciou a definição cinco tipos de atividades formadoras de ambientes tecnogênicos ${ }^{5}$ na Ilha, sendo: a agricultura, os aterros, as estradas, os solos expostos e a urbanização de maneira que, em 2013, os ambientes formados pela urbanização representavam 76,10\% dos depósitos tecnogênicos da área de estudo, que recobriam uma área de $69,58 \mathrm{~km}^{2}$, ou $16,48 \%$ do território da Ilha, conforme apresentado a seguir na Figura 18.

\footnotetext{
${ }^{5}$ Conforme o conceito de PELOGGIA (1997, p.258), a geologia do Tecnógeno concentra-se no estudo das feições e dos depósitos ditos tecnogênicos, sendo aqueles gerados diretamente ou influenciados pela atividade humana, e também pelos seus processos específicos, que atuam sobre os próprios depósitos tecnogênicos assim como sobre maciços e relevos pré-existentes.
} 


\begin{tabular}{|c|c|c|}
\hline \multicolumn{3}{|c|}{ Evolução Populacional (1970 - 2017) } \\
\hline Ano & Efetivo & \% do efetivo atual \\
\hline 1970 & 138.337 & 28,47 \\
\hline 1980 & 187.800 & 38,65 \\
\hline 1991 & 255.390 & 52,57 \\
\hline 1996 & 268.720 & 55,31 \\
\hline 2000 & 342.315 & 70,46 \\
\hline 2007 & 396.723 & 81,66 \\
\hline 2010 & 421.240 & 86,70 \\
\hline 2015 & 469.690 & 96,68 \\
\hline 2016 & 477.798 & 98,35 \\
\hline 2017 & 485.838 & 100 \\
\hline
\end{tabular}

Quadro 2 - Evolução da população de Florianópolis entre os anos de 1970 e 2017 de acordo com os censos e contagens da população do IBGE (Fonte dos dados censitários: IBGE, 2017).

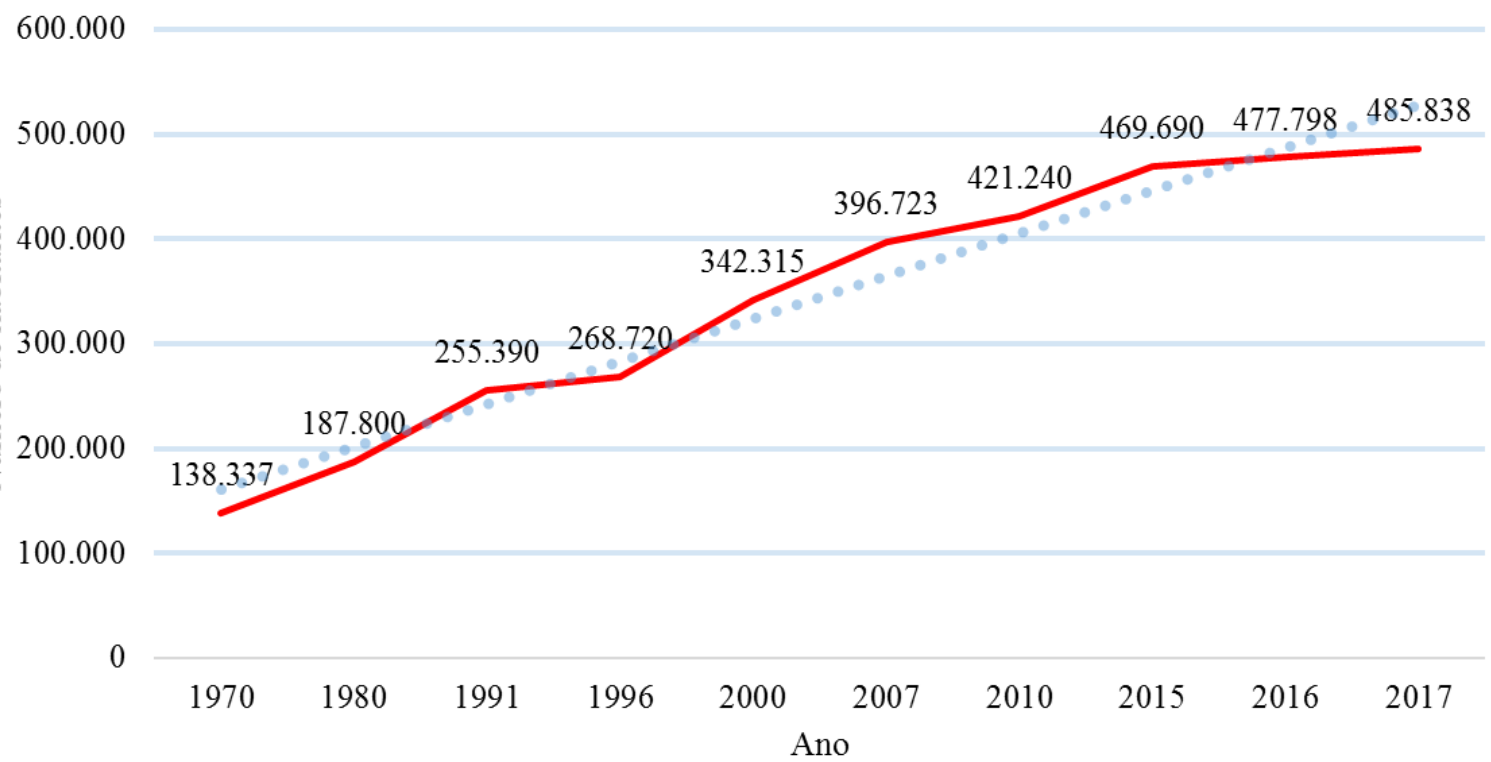

Gráfico 2 - Tendência do aumento populacional do município de Florianópolis entre os anos de 1970 e 2017, de acordo com os censos e contagens da população do IBGE (Fonte dos dados censitários: IBGE, 2017). 


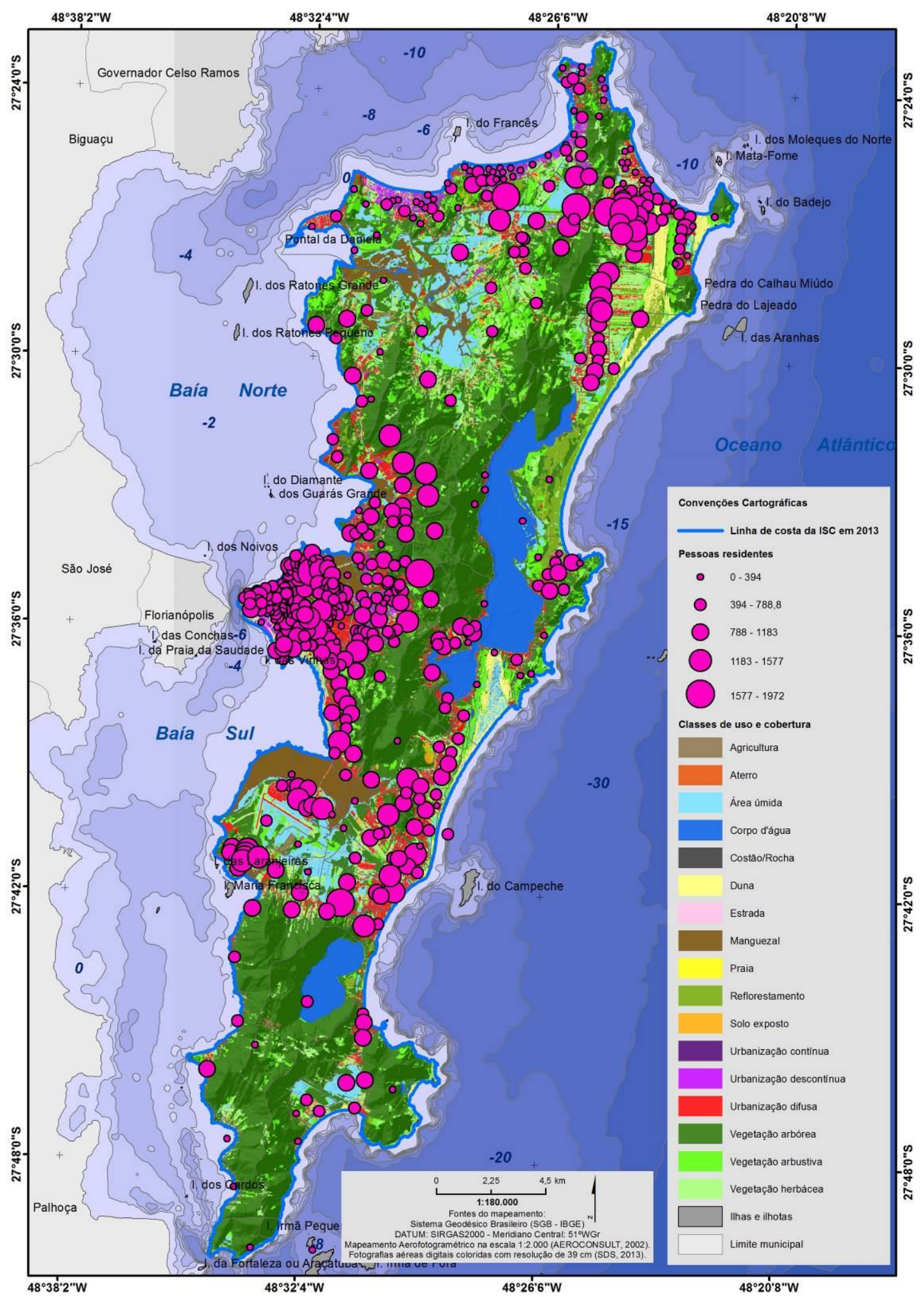

Figura 17 - Número de pessoas residentes (pontos em magenta com intervalos entre 0 e 394 até 1.577 e 1.972 habitantes) por setor censitário do IBGE em 2010 na área de estudo (IBGE, 2016) (Fonte: NEVES, 2017). 


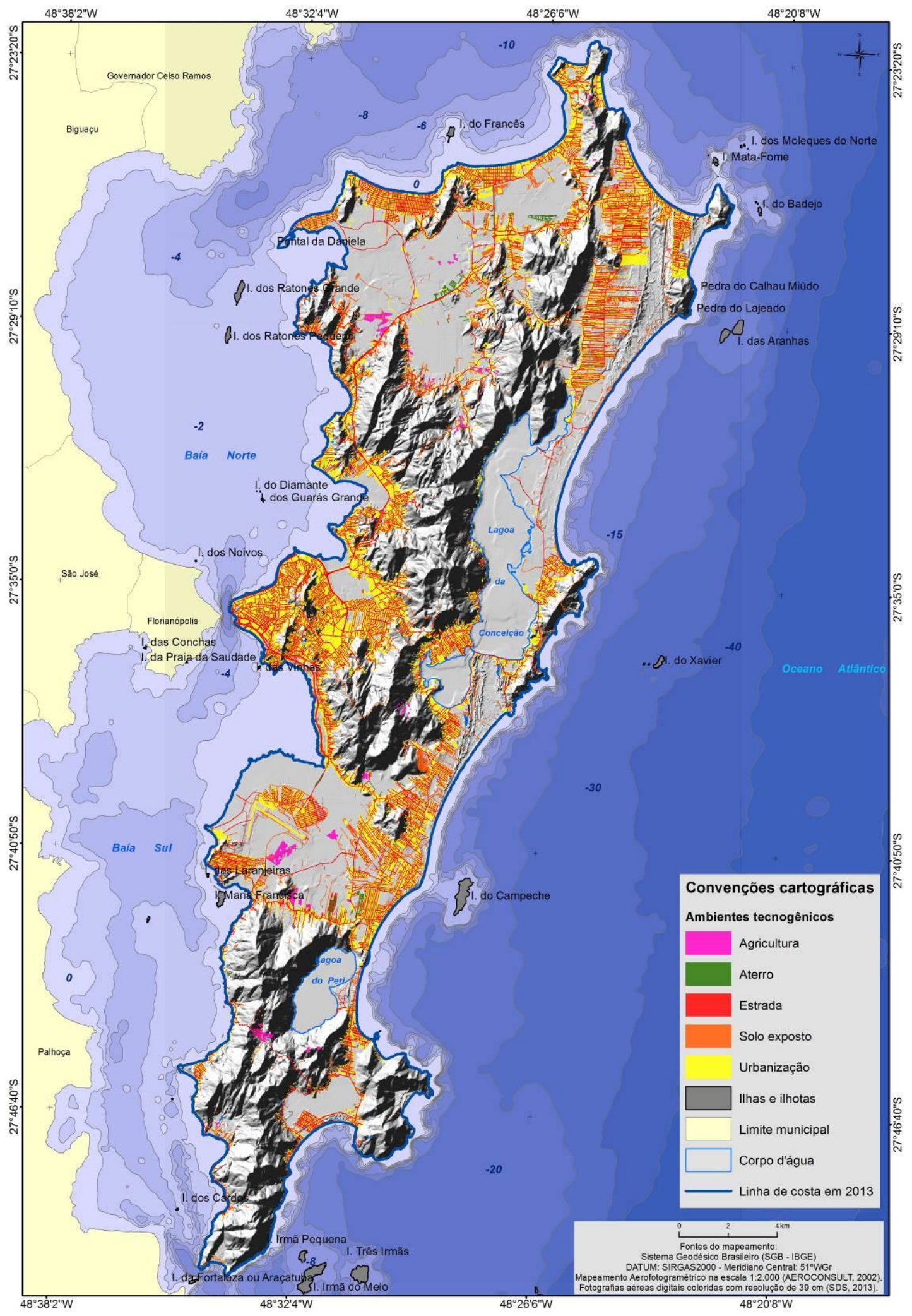

Figura 18 - Mapeamento das classes: agricultura; aterro; estrada; solo exposto e urbanização, que representam os depósitos tecnogênicos da área de estudo (Fonte: NEVES, 2017).

\section{Considerações e agradecimentos}

O mapeamento que produzimos gerou uma base cartográfica inédita do uso e da cobertura da terra para toda Ilha de Santa Catarina. Os dados elaborados na escala 1:2.000 por 
esta pesquisa serão disponibilizados para acesso público junto ao IPUF e ao IBGE, no formato shapefile, ou podem ser solicitados através do e-mail do primeiro autor.

Os autores agradecem à Coordenação de Aperfeiçoamento de Pessoal de Nível Superior (CAPES) pela concessão de bolsa de doutorado-sanduíche no exterior (PDSE-CAPES) que possibilitou o trabalho conjunto do Programa de Pós-graduação em Geografia da Universidade Federal de Santa Catarina (PPGGeo - UFSC) com o Laboratório de Estudo das Estruturas, Processos de Adaptação e Modificações do Espaço (UMR 7300 ESPACE) da Universidade de Nice Sophia Antipolis, no Sul da França.

\section{Referências Bibliográficas}

CAMPOS, N. J. de. Terras comunais na Ilha e Santa Catarina. 162 p. Florianópolis: Editora da Universidade Federal de Santa Catarina, 1991. il.

CARUSO, M. M. L. O desmatamento da Ilha de Santa Catarina de 1.500 aos dias atuais. $2^{\circ}$ Ed. 158 p. Florianópolis: Editora da Universidade Federal de Santa Catarina, 1990. il. EEA - EUROPEAN ENVIRONMENT AGENCY. Corine land cover technical guide. 94 p. il. Luxembourg: European Environment Agency, 1999.

ENGEMAP - ENGENHARIA E MAPEAMENTO. Case Secretaria de Estado do Desenvolvimento Econômico e Sustentável (SDS): Projeto de Mapeamento do Estado e Santa Catarina. Disponível em: http://engemap.com.br/v3/case-sds. Acesso em: 25 de out. 2017.

FERRETTI, O. E. Os espaços de natureza protegida na Ilha de Santa Catarina, Brasil. 349 p. Tese (Doutorado em Geografia) - Programa de Pós-graduação em Geografia, Universidade Federal de Santa Catarina, Florianópolis. 2013.

FLORIANÓPOLIS. Lei $n^{\circ}$ 2193/85. Dispõe sobre o zoneamento o uso e a ocupação do solo nos balneários da Ilha de Santa Catarina. Lex: Instituto de Planejamento Urbano de Florianópolis (IPUF), Florianópolis, v. único, p. 53, jan., 1985. Legislação Municipal.

FLORIANÓPOLIS. Lei Complementar $n^{\circ} 1 / 97$. Dispõe sobre o zoneamento, o uso e a ocupação do solo no distrito sede de Florianópolis, e dá outras providências. Lex: Instituto de Planejamento Urbano de Florianópolis (IPUF), Florianópolis, v. único, p. 59, out., 1997. Legislação Municipal.

FLORIANÓPOLIS. Lei Complementar n482, de 17 de janeiro de 2014. Institui o Plano Diretor de Urbanismo do Município de Florianópolis que dispõe sobre a política de desenvolvimento urbano, o plano de uso e ocupação, os instrumentos urbanísticos e o sistema de gestão. Lex: Instituto de Planejamento Urbano de Florianópolis (IPUF), Florianópolis, v. único, p. 110, jan., 2014. Legislação Municipal. Disponível em: http://www.pmf.sc.gov.br/arquivos/arquivos/pdf/04_02_2014_12.01.39.ae8afdb369c91e13ca 6efcc14b25e055.pdf. Acesso em: 25 de out. 2017.

FURLANETTI, T. Ações atuais de Mapeamento do Estado de Santa Catarina Disponível em: http://www.concar.gov.br/temp/17a_Pl_CONCAR_21set2011_Plano_SC.pdf. Acesso em: 25 de out. 2017.

IBGE - INSTITUTO BRASILEIRO DE GEOGRAFIA E ESTATÍSTICA. Manual Técnico de Uso da Terra. $2^{\circ}$ Ed. Diretoria de Geociências - IBGE, 91 p. il. Rio de Janeiro: 2006. IBGE - INSTITUTO BRASILEIRO DE GEOGRAFIA E ESTATÍSTICA. Sinopse dos setores do Censo 2010. Disponível em: http://www.censo2010.ibge.gov.br/sinopseporsetores/?nivel=st. Acesso em: 15 de out. 2016. 
IBGE - INSTITUTO BRASILEIRO DE GEOGRAFIA E ESTATÍSTICA. Apresenta informações sobre o município de Florianópolis. Disponível em: <https://cidades.ibge.gov.br>. Acesso em: 25 de out. 2017.

IPUF - INSTITUTO DE PLANEJAMENTO URBANO DE FLORIANÓPOLIS. Restituição Aerofotogramétrica do Município de Florianópolis. Florianópolis: 449 plantas topográficas: 42 x 59,4 cm. Escala: 1:2:000. 2002.

NEVES. J. Uso da terra e urbanização dos ambientes costeiros na Ilha de Santa Catarina, SC, Brasil. 364 p. Tese (Doutorado em Geografia) - Programa de Pós-graduação em Geografia, Universidade Federal de Santa Catarina, Florianópolis. 2017.

PELOGGIA, A. U. G. A ação do homem enquanto ponto fundamental da geologia do Tecnógeno: proposição teórica básica e discussão acerca do Caso do município de São Paulo. In: Revista Brasileira de Geociências, 1997, 27(3):257-268.

SDS - SECRETARIA DE ESTADO DO DESENVOLVIMENTO ECONÔMICO E SUSTENTÁVEL. Projeto de Mapeamento do Estado de Santa Catarina. Disponível em: <http://sigsc.sds.sc.gov.br>. Acesso em: 07 de out. 2016.

VOIRON-CANICIO, C. Analyse spatiale et analyse d'images par la morphologie mathématique. Montpellier: GIP RECLUS, 1995, 190p. il.

VOIRON-CANICIO, C. Modélisation spatio-morphologique de l'urbanisation du litoral languedocien. Université de Nice - UMR ESPACE, Rapport d'étude. Nice, 2006, 15 p. Disponível em: <https://hal.archives-ouvertes.fr/hal-00130991/document>. Acessado em 21 de setembro de 2017.

Recebido em novembro de 2016.

Aceito em dezembro de 2016. 